\title{
Does international trade improve environmental efficiency? An application of a super slacks-based measure of efficiency
}

\author{
Satoshi Honma
}

\author{
Correspondence: \\ honmasatoshi999@gmail.com \\ School of Political Science and \\ Economics, Department of \\ Economics, Tokai University, 4-1-1 \\ Kitakaname, Hiratsuka 259-1292, \\ Japan
}

\begin{abstract}
This study analyzes the impact of international trade on environmental efficiency. Using a data envelopment analysis (DEA) model that allows us to treat undesirable outputs and super-efficiency beyond unity, we measure the environmental efficiency of four typical air pollutants - $\mathrm{SO}_{2}, \mathrm{NOx}$, particulate matter $10 \mu \mathrm{m}$ or less in diameter, and $\mathrm{CO}_{2}$ - for 98 countries for the period 1970-2008. The resulting environmental efficiency is regressed on income, capital-labor ratio, and trade openness. The panel regression results reveal that trade openness is positively correlated to the environmental efficiency. However, the impact of trade openness on environmental efficiency varies across countries depending on their relative per capita income. The estimated results show that the higher the relative income per capita, the more the benefit of trade on the environmental efficiency.
\end{abstract}

Keywords: Data envelopment analysis; Environmental efficiency; Pollution haven hypothesis; Super-efficiency

JEL classification: Q56; Q53; Q54

\section{Springer}

\section{Background}

The impact of trade liberalization on the environment has attracted considerable attention from policy makers and academic researchers. Grossman and Krueger (1993) emphasize the role of international trade on the environment and decompose the effects of trade openness into three separate mechanisms as follows: scale, technique, and composition effects. The scale effect refers to an increase in pollution emissions resulting from economic expansion by trade openness. The technique effect refers to a reduction in pollution emissions due to the demand for stricter environmental regulations with rising income. The composition effect refers to a change in the industrial structure through trade openness. In particular, the pollution haven hypothesis $(\mathrm{PHH})$, which asserts that dirtier industries move from developed countries to developing countries, remains controversial. The seminal paper of Antweiler et al. (2001) regresses pollution concentration on representative variables of the above three effects. Their empirical results show a positive scale effect, a negative technique effect, and a negative composition effect. However, the composition effect caused by trade varies across countries depending on relative income and factor abundance (see also Cole and Elliott 2003; Frankel and Rose, 2005; and Managi et al. 2009). 
In the abovementioned previous studies, per capita pollution emission is regressed on variables representing scale, technique, and composition effects. Because emission and income are a consequence of the production process, an empirical strategy to regress pollution emissions on income and trade openness fails to understand the underlying production process (Zaim and Taskin, 2000) ${ }^{1}$. Therefore, we take environmental efficiency as a dependent variable. As long as pollutants are not freely disposable (weak disposability), reducing pollutants involves a transformation of the production process, which requires sacrificing the output and additional inputs. Taking environmental efficiency as a dependent variable allows us to measure an alternative measure of environmental degradation instead of pollution emissions per capita.

This study aims to investigate whether international trade is beneficial to the environment, using environmental efficiency. Therefore, we use a super environmental efficiency index that modifies Li et al. (2013) model and apply it to 98 countries, including developed and developing countries, for 1970-2008 and for the following four pollutants: $\mathrm{SO}_{2}$, $\mathrm{NO}_{\mathrm{x}}$, particulate matter $10 \mu \mathrm{m}$ or less in diameter (PM10), and $\mathrm{CO}_{2}$. To examine the impacts of trade on environmental efficiency, we regress the efficiency values on trade openness and other variables. Because the scores in the traditional data envelopment analysis (DEA) models censored at unity, when one uses the obtained scores as a dependent variable in the regression one should resort to Tobit estimation. However, the Tobit estimation applied in fixed effects in the panel data involves complications and cannot consistently estimate fixed effects. Because the super-efficiency model assigns an efficiency score larger than unity to the efficient units, the obtained scores are tractable in the second-stage analysis. This study is the first one to apply the super slacks-based measure (SBM) efficiency measurement for the world dataset in environmental economics.

Traditionally, environmental performance involving desirable and undesirable outputs has been analyzed by the directional distance function approach (Färe et al. 1993; Chung et al. 1997; Picazo-Tadeo et al. 2005). However, it cannot directly treat input excesses and output shortages, which are termed "slacks." Tone (2001) proposes the SBM model, which is a non-radial data envelopment analysis (DEA) model. In measuring environmental performance, non-radial efficiency measurement in the SBM model exerts more discriminating power than the radial one in traditional DEA models (Zhou et al. 2006; Wei et al. 2012). Namely, some of the efficient decision making units (DMUs) in traditional models become inefficient in the SBM model. Furthermore, the super SBM efficiency model proposed by Tone (2002) has a higher level of discriminating power than the SBM model because it can rank the efficient DMUs, allowing above-unity scores. Recently, SBM efficiency is applied to environment and energy studies; for example, OECD countries (Zhou et al. 2006), China (Choi et al. 2012; Li and Hu, 2012; Chang et al. 2013; Li et al. 2013). Li et al. (2013), construct a super SBM efficiency measurement with undesirable outputs and apply it to China's regional environmental efficiency. However, its definition (Eq. 3 in their paper) seems to be inadequate. We give the right definition.

The rest of the paper is organized as follows. Section 2 describes the paper's methodology and data. Section 3 presents the efficiency results. Section 4 investigates the

\footnotetext{
${ }^{1}$ Another problem related to estimation of the $\mathrm{PHH}$ is endogeneity of income and trade openness. Managi et al. (2009) successfully estimate the overall impact of trade openness on the environment, using a differentiated generalized method of moments (GMM) in which predicted income and trade openness are taken as instrument variables. Based on their technique, Tsurumi and Managi (2014) find a statistically significant effect of trade openness on deforestation.
} 
determinants of environmental efficiency in the panel regression. Section 5 concludes the study with a brief summary.

\section{Methods}

This section explains a super SBM efficiency model, redefining Li et al. (2013) model, in which undesirable outputs can be treated to measure environmental efficiency in the world economy.

\subsection{SBM efficiency without undesirable outputs}

To begin with, we start with a description of SBM models without undesirable outputs. Assume a DMU having $k$ input, $\mathbf{x}_{i}=\left(x_{1 i}, \cdots x_{k i}\right), m$ desirable outputs, $\mathbf{y}_{i}^{g}=\left(y_{1 i}^{g}, \cdots, y_{m i}^{g}\right)$, and $n$ undesirable outputs, $\mathbf{y}_{i}^{b}=\left(y_{1 i}^{b}, \cdots, y_{n i}^{b}\right)$. Then, the inputs, desirable, and undesirable outputs are denoted by $\mathbf{X}=\left\{x_{j i}\right\} \in \mathbf{R}^{k \times h}, \mathbf{Y}^{g}=\left\{y_{j i}^{g}\right\} \in \mathbf{R}^{m \times h}$, and $\mathbf{Y}^{b}=\left\{y_{j i}^{b}\right\} \in \mathbf{R}^{n \times h}$, respectively. Assume $\mathbf{X}>0, \mathbf{Y}^{g}>0$, and $\mathbf{Y}^{b}>0$. Then, assuming constant returns to the scale, the production possibility set is given by

$$
P=\left\{\mathbf{x}, \mathbf{y}^{g}, \mathbf{y}^{b} \mid \mathbf{x} \geq X \boldsymbol{\lambda}, \mathbf{y}^{g} \leq Y^{g} \boldsymbol{\lambda}, \mathbf{y}^{b} \geq Y^{b} \boldsymbol{\lambda}, \boldsymbol{\lambda} \geq \mathbf{0}\right\},
$$

where $\boldsymbol{\lambda}=\left(\lambda_{1}, \cdots, \lambda_{h}\right)$ is the intensity vector.

Tone (2001) proposes the SBM efficiency without undesirable outputs as

$$
\begin{gathered}
\theta^{g}=\min \frac{1-\frac{1}{k} \sum_{j=1}^{k} \frac{s_{j}^{-}}{x_{j i}}}{1+\frac{1}{m} \sum_{j=1}^{m} \frac{s_{j}^{g}}{y_{j i}^{g}}} \\
\text { s.t. } \boldsymbol{x}_{i}=X \boldsymbol{\lambda}+\boldsymbol{s}^{-} \\
\mathbf{y}_{i}^{g}=Y^{g} \boldsymbol{\lambda}-\mathbf{s}^{g} \\
\mathbf{s}^{-}, \mathbf{s}^{g}, \boldsymbol{\lambda} \geq \mathbf{0},
\end{gathered}
$$

where $\mathbf{s}^{-} \in R^{k}$ and $\mathbf{s}^{g} \in R^{m}$ denote the input excesses and output shortfalls, respectively. They are called as the slacks. Obviously, $\theta^{g}$ satisfies $0<\theta^{g} \leq 1$ and reaches unity if and only if all slacks are zero.

To enhance discriminating power among the efficient DMUs, Tone (2002) formulates the super SBM efficiency model. Assuming a DMU 0 is SBM-efficient, the super SBM efficiency is given by

$$
\begin{gathered}
\theta^{g *}=\min \frac{\frac{1}{k} \sum_{j=1}^{k} \frac{\bar{x}_{j}}{x_{j 0}}}{\frac{1}{m} \sum_{j=1}^{m} \frac{\bar{y}_{j}^{g}}{y_{j 0}^{g}}} \\
\text { s.t } \overline{\mathbf{x}} \geq \sum_{\substack{i=1 \\
h \\
i \neq 0}}^{h} \lambda_{i} \mathbf{x}_{i}, \\
\overline{\mathbf{y}} \leq \sum_{\substack{i=1 \\
i \neq 0}}^{h} \lambda_{i} \mathbf{y}^{g}{ }_{i}, \\
\overline{\mathbf{x}} \geq \mathbf{x}_{0}, \\
\overline{\mathbf{y}} \leq \mathbf{y}_{0}, \\
\overline{\mathbf{y}} \geq 0, \\
\mathbf{\lambda} \geq 0
\end{gathered}
$$

The numerator indicates a mean expansion rate of $\mathbf{x}_{0}$ to $\overline{\mathbf{x}}$, and the denominator indicates a mean reduction rate of $\mathbf{y}_{0}$ to $\overline{\mathbf{y}}$. 


\subsection{SBM efficiency with undesirable outputs}

We introduce undesirable outputs in SBM efficiency models. Extending the SBM model in his previous study (Tone, 2001), Tone (2004) proposes an SBM model with undesirable outputs

$$
\begin{aligned}
& \rho=\min \frac{1-\frac{1}{k} \sum_{j=1}^{k} \frac{s_{j}^{-}}{x_{j 0}}}{1+\frac{1}{m+n}\left(\sum_{j=1}^{m} \frac{s_{j}^{g}}{y_{j 0}^{g}}+\sum_{j=1}^{n} \frac{s_{j}^{b}}{y_{j 0}^{b}}\right)} \\
& \text { s.t. } \boldsymbol{x}_{i}=X \boldsymbol{\lambda}+\boldsymbol{s}^{-}, \\
& \mathbf{y}_{i}^{g}=Y^{g} \boldsymbol{\lambda}-\mathbf{s}^{g}, \\
& \mathbf{y}_{i}^{b}=Y^{b} \boldsymbol{\lambda}+\mathbf{s}^{b}, \\
& \mathbf{s}^{-}, \mathbf{s}^{g}, \mathbf{s}^{b}, \boldsymbol{\lambda} \geq \mathbf{0},
\end{aligned}
$$

where $\mathbf{s}^{b} \in R^{n}$ denotes excesses for undesirable outputs. $\rho$ takes unity only if all slacks are zero. Rearranging (3) as

$$
\rho=\frac{\frac{1}{k} \sum_{j=1}^{k} \frac{x_{j 0}-s_{j}^{-}}{x_{j 0}}}{\frac{1}{m} \sum_{j=1}^{m} \frac{y_{j 0}^{g}+s_{j}^{g}}{y_{j 0}^{g}}+\frac{1}{n} \sum_{j=1}^{n} \frac{y_{j 0}^{b}+s_{j}^{b}}{y_{j 0}^{b}}}
$$

Apparently, the numerator indicates the mean reduction rate of inputs, which can be interpreted as input mix inefficiencies. The first term in the denominator indicates the mean expansion rate of desirable outputs, and the second term reflects the mean reduction rate of undesirable outputs. The sum of the first and second terms in the denominator can be interpreted as output mix inefficiencies. In this way, model (4) successfully deals with undesirable outputs; however, we cannot discriminate efficient DMUs any more.

To discriminate the efficient DMUs when undesirable outputs are included, Li et al. (2013) propose a super SBM model with the undesirable outputs SBM model. Before introducing the model, it is useful to define the production set for evaluating a DMU that takes $\rho=1$, as follows:

$$
\bar{P} \backslash\left(\mathbf{x}_{0}, \mathbf{y}_{0}\right)=P\left(\mathbf{x}_{0}, \mathbf{y}_{0}\right) \backslash\left(\mathbf{x}_{0}, \mathbf{y}_{0}\right) \cap\left\{\overline{\mathbf{x}} \geq \mathbf{x}_{0}, \overline{\mathbf{y}}^{g} \leq \mathbf{y}_{0}^{g}, \overline{\mathbf{y}}^{b} \geq \mathbf{y}_{0}^{b}\right\},
$$

where $P \backslash\left(\mathbf{x}_{0}, \mathbf{y}_{0}\right)$ is defined as a production possibility set spanned by $\left(\mathbf{X}, \mathbf{Y}^{g}, \mathbf{Y}^{b}\right)$, excluding $\left(\mathbf{x}_{0}, \mathbf{y}_{0}\right)$, i.e.,

$$
P \backslash\left(\mathbf{x}_{0}, \mathbf{y}_{0}\right)=\left\{\overline{\mathbf{x}}, \overline{\mathbf{y}}^{g}, \overline{\mathbf{y}}^{b} \mid \overline{\mathbf{x}} \geq \sum_{\substack{i=1 \\ i \neq 0}}^{h} \lambda_{j} \mathbf{x}_{j}, \overline{\mathbf{y}}^{g} \leq \sum_{\substack{i=1 \\ i \neq 0}}^{h} \lambda_{j} \mathbf{y}_{j}^{g}, \overline{\mathbf{y}}^{b} \geq \sum_{\substack{i=1 \\ i \neq 0}}^{h} \lambda_{j} \mathbf{y}_{j}^{b}, \mathbf{\lambda} \geq \mathbf{0}\right\} .
$$

Using the notations in this study, Li et al. (2013) proposed the super SBM environmental efficiency (Eq. 3 in their paper): 


$$
\begin{gathered}
\eta^{*}=\min \frac{\frac{1}{k} \sum_{j=1}^{k} \frac{\bar{x}_{j}}{\bar{x}_{j 0}}}{\frac{1}{m} \sum_{j=1}^{m} \frac{\bar{y}_{j}^{g}}{y_{j 0}^{g}}+\frac{1}{n} \sum_{j=1}^{n} \frac{\bar{y}_{j}^{b}}{y_{j 0}^{b}}} \\
\text { s.t. } \overline{\mathbf{x}} \geq \sum_{\substack{i=1 \\
i \neq 0}}^{h} \lambda_{i} \mathbf{x}_{i}, \\
\overline{\mathbf{y}}^{g} \leq \sum_{i=1,}^{h} \lambda_{i} \mathbf{y}_{i}^{g}, \\
i \neq 0 \\
\overline{\mathbf{y}}^{b} \geq \sum_{i=1,}^{h} \lambda_{i} \mathbf{y}_{i}^{b}, \\
i \neq 0 \\
\overline{\mathbf{x}}^{b} \geq \mathbf{x}_{0}, \\
\overline{\mathbf{y}}^{g} \leq \mathbf{y}_{0}, \\
\overline{\mathbf{y}}^{b} \geq \mathbf{y}_{0} \\
\overline{\mathbf{y}}^{g} \geq 0, \\
\boldsymbol{\lambda} \geq 0 . \\
\end{gathered}
$$

for DMU 0, which has unity score in (3). In this equation, however, the less polluting the DMU, the smaller is the efficiency value as the denominator includes "the possible expansion rate" within the production possibility set excluding DMU 0. Actually, scores calculated by (5) is near zero because $\bar{y}_{j}^{b}$ could be large values.

We redefine a super environmental efficiency with undesirable outputs, as follows:

$$
\eta^{* *}=\min \frac{\frac{1}{k} \sum_{j=1}^{k} \frac{\bar{x}_{j}}{x_{j 0}}}{\frac{1}{m} \sum_{j=1}^{m} \frac{\bar{y}_{j}^{g}}{y_{j 0}^{g}}+\frac{1}{n} \sum_{j=1}^{n}\left(1-\frac{\bar{y}_{j}^{b}-y_{j 0}^{b}}{y_{j 0}^{b}}\right)}
$$

where the constraint conditions are the same as those in Eq. 5 . Here, we modify the second term of the denominator in Eq. 5. The numerator indicates a mean expansion rate of $\mathbf{x}_{0}$ to $\overline{\mathbf{x}}$, which implies the mixed input superiority of DMU 0 . On the other hand, the first term in the denominator indicates a mean reduction rate of $\mathbf{y}_{0}^{g}$ to $\overline{\mathbf{y}}^{g}$. The second term in the denominator indicates a mean of one minus expansion rate of $\mathbf{y}_{0}^{b}$ to $\overline{\mathbf{y}}^{b}$. Then, the denominator implies the mixed output superiority of DMU 0. Note that the efficiency values in year $t$ are calculated on the basis of the production possibility set in year $t$. The denominator of Eq. 5 should be replaced with $\frac{1}{m}$ $\sum_{j=1}^{m} \frac{\bar{y}_{j}^{g}}{y_{j 0}^{g}}+\frac{1}{n} \sum_{j=1}^{n} \frac{y_{j 0}^{b}}{\bar{y}_{j}^{b}}$, if so, the solution is equivalent to (6).

Because this study analyzes the world dataset, the variable returns to scale assumption is more suitable for the analysis than the constant returns to scale. A convex constraint

$$
\sum_{i=1}^{h} \lambda_{i}=1
$$

is added to Eq. 6 to restrict the production possibility to the variable returns to scale technology. 


\subsection{Empirical strategies}

We examine the determinants of environmental efficiency on the basis of the following estimated equation ${ }^{2}$ :

$$
\left\{E F_{i t}=\beta_{0}+\beta_{1} \ln I_{i t}+\beta_{2} \ln (K / L)_{i t}+\beta_{3} \ln T_{i t}+\beta_{4} \ln T_{i t} \cdot R I_{i t}+\beta_{5} \ln T_{i t} \cdot R K L_{i t}+\varepsilon_{i t},\right.
$$

where $i$ is a country index; $t$ is year; $E F$ is environmental efficiency; $I$ is one-year lagged per capita income; $(K / L)$ is a country's one-year lagged capital-labor ratio; $T$ is trade openness; $R I$ is the relative GDP per capita, which is defined as the ratio of the country's GDP per capita to the world average one in each year; $R(K / L)$ is the relative capital-labor ratio; and $\varepsilon_{i t}$ is the disturbance term. Because GDP, labor, and capital stock are used to derive the efficiency in the first-stage analysis, we use one-year lagged per capita income and capital-labor ratio as the independent variables in the second-stage analysis.

The second term on the right-hand side in Eq. 7 represents the scale-technique effects. As with Cole and Elliott (2003), we cannot separate the scale and technique effects, because income per capita (variable I) is a proxy variable for both the scale and income level. The third term captures the direct composition effect that reflects a fact that capital abundant countries specialize in the dirty industry because capital intensity and pollution intensity are highly correlated. The forth to sixth terms are related to the trade effects. The forth term captures the direct trade effect, whereas the fifth and sixth terms capture the trade-induced scaletechnique and composition effects, respectively. They represent how much the impacts of trade openness on environmental efficiency depend on a country's relative per capita income and capital-labor ratio.

\subsection{Data}

In our DEA model, there are two inputs-labor and capital stock-,and GDP is the sole desirable output. $\mathrm{SO}_{2}, \mathrm{NO}_{\mathrm{x}}, \mathrm{PM} 10$, and $\mathrm{CO}_{2}$ emissions are taken as undesirable outputs. Data on GDP, labor, and capital stock are taken from the Penn World Table 8.0. All monetary values are 2005 constant US dollars. Data on the four pollution emissions are obtained from the Emissions Database for Global Atmospheric Research (EDGAR) 4.2 database. The dataset for the DEA is a balanced panel data from 1970 to 2008 for 98 countries. The data consist of 30 OECD countries and 68 non-OECD countries. Figure S1 in Additional file 1 provides a list of the countries.

For the second-stage analysis, data on per capita income are taken from GDP per capita in PWT 8.0. However, while data on GDP in the first-stage analysis use outputside GDP in PWT 8.0, those in the second-stage regression are calculated by the expenditure GDP divided by the population. Taking data on alternative definitions of GDP will mitigate the endogeneity problem. Trade openness (the sum of export and import values divided by the GDP) is taken as an explanatory variable in the regression, which is obtained from the World Development Indicators 2013 of the

\footnotetext{
${ }^{2}$ Estimation results including both income and its squared were insignificant for many specifications. Therefore, we do not include the squared term in Eq. 7, unlike the previous studies to test the environmental Kuznets curve hypothesis with respect to environmental efficiency (Zaim and Taskin, 2000; Managi and Jena 2008; Halkos and Tzeremes, 2009; 2011).
} 
World Bank ${ }^{3}$. Table 1 reports the summary of statistics of input and output variables for DEA analysis and the explained and explanatory variables for the regression.

\section{Results and discussion}

\subsection{Environmental efficiency results}

The environmental efficiency indices for each year are computed by the production possibility set in that year. Note that the efficiency scores in a year are relative comparisons within the same year. Figure $\mathrm{S} 1$ in Additional file 1 provides the $\mathrm{SO}_{2}$ and $\mathrm{CO}_{2}$ environmental efficiency scores of 98 countries. Among 3822 (98 countries by 39 years) evaluation scores, for $\mathrm{SO}_{2}, 664$ observations are efficient and have scores larger than unity.

Figure 1 shows the median environmental efficiency values for $\mathrm{SO}_{2}$ during the sample period $^{4}$. As shown in Fig. 1, the median environmental efficiency of the OECD and nonOECD countries slightly increases at almost the same rate until 1978. Since 1979, however, they diverge for the rest of the sample period. The median environmental efficiency of the OECD countries is always higher than that of the non-OECD countries in each year from 1979 to 2008. These features are also the same for $\mathrm{NO}_{x}, \mathrm{PM10}$, and $\mathrm{CO}_{2}$.

\subsection{Determinants of environmental efficiency}

Table 2 presents the estimated results for four pollutants, namely $\mathrm{SO}_{2}$, NOx, PM10, and $\mathrm{CO}_{2}$. The results without time dummies are presented in the left four columns in Table 2. The Hausman test prefers the fixed effects models to the random effects models for each of the four pollutants. First, the coefficients of income per capita are positive values for all pollutants at the $1 \%$ significant level. Because the estimated equations are no log-log forms, this implies that a $1 \%$ increase in income improves the environmental efficiency by 0.00221 (PM10) to $0.00389\left(\mathrm{CO}_{2}\right)$. Second, the coefficients of capital-labor ratio are almost negative, but significant only for $\mathrm{SO}_{2}$ in the random effects. Third, all the coefficients of trade have positive signs except for $\mathrm{CO}_{2}$, and is significant only for $\mathrm{SO}_{2}$.

To capture unobservable factors in the world economy, we introduce time dummies in the regression. The right four columns in Table 2 indicate estimation results with time dummies. The Hausman tests do not reject the null hypothesis that the random effects model is consistent. First, as well as the results without time dummies, the coefficients of per capita income have positive signs for all pollutants at the $1 \%$ level. For each case, the magnitude of the coefficient with time dummies is larger than that of the coefficient without those dummies. Second, in contrast to the results without time dummies, the coefficients of capital-labor ratio is negative and statistically significant at the $1 \%$ level for all pollutants and both specifications. This implies that the composition effect deteriorates the environmental efficiency. Third, the coefficients of openness except for $\mathrm{CO}_{2}$ remain positive, but become statistically insignificance.

In conclusion, we find some evidence for the scale-technique effect and composition effect on the environmental efficiency. The former is positively correlated with the environmental efficiency while the latter is negatively correlated. Only for $\mathrm{SO}_{2}$, we observe that

\footnotetext{
${ }^{3}$ Data on Taiwan are taken from the Taiwanese government's official site.

${ }^{4}$ Because mean values are affected by extreme values, I examine median efficiency values.
} 
Table 1 Summary of statistics of input and output variables

\begin{tabular}{lllllll}
\hline Variable & Dimension & Obs. & Mean & SD & Min & Max \\
\hline Real GDP & mil. 2005US\$ & 3822 & $338,769.200$ & $1,018,679.000$ & 1206.338 & $1.31 \mathrm{E}+07$ \\
Real GDP per capita & 2005US\$ & 3822 & $10,545.990$ & $11,845.310$ & 199.208 & $116,423.5$ \\
Labor & million & 3822 & 19.877 & 69.734 & 0.045 & $7.72 \mathrm{E}+02$ \\
Capital stock & mil. 2005US\$ & 3822 & $1,019,600.000$ & $3,225,986.000$ & 1847.514 & $4.01 \mathrm{E}+07$ \\
Capital-labor ratio & 2005US\$/worker & 3822 & $77,730.800$ & $85,428.740$ & 1131.321 & $868,037.4$ \\
Trade openess & \% & 3518 & 71.004 & 52.373 & 0.703 & 460.4711 \\
SO2 emissions & Giga gram & 3822 & 0.973 & 3.070 & 0.001 & 39.903 \\
Nox emissions & Giga gram & 3822 & 0.766 & 2.186 & 0.003 & 20.742 \\
PM10 emissions & Giga gram & 3822 & 0.811 & 1.881 & 0.000 & 19.334 \\
CO2 emissions & Giga gram & 3822 & 222.401 & 660.099 & 0.033 & 7809.190 \\
\hline
\end{tabular}

the trade is beneficial to the environment. We further examine impacts of trade on the environment, adding interaction variables of trade.

To explore how much effect the relative income and factor-endowment has on the trade effect on environmental efficiency, trade openness is interacted with a country's relative income and capital-labor ratio in the regression. Table 3 presents the estimation results with and without time dummies. The results without time dummies are shown in the left four columns in Table 3. The coefficients of trade openness are positive for $\mathrm{SO}_{2}, \mathrm{NOx}$, and PM10, but statistically significant only for $\mathrm{SO}_{2}$. It is noteworthy that the coefficients of the interaction term between trade openness and relative income per capita for all pollutants and for all specifications are statistically positive. It indicates that the higher the relative per capita income, the more the benefit of trade on the environmental efficiency.

The results with time dummies are shown in the right four columns in Table 3. As well as the results without the interaction terms, all of the estimated coefficients of capital-labor ratio remain significantly negative and statistically significant in the right four columns in Table 2. The coefficients of the interaction term between trade openness and relative income per capita except for $\mathrm{SO}_{2}$ are positive and statistically significant. Note that the coefficients of the interaction term between trade openness and relative capital-labor ratio are insignificant for all

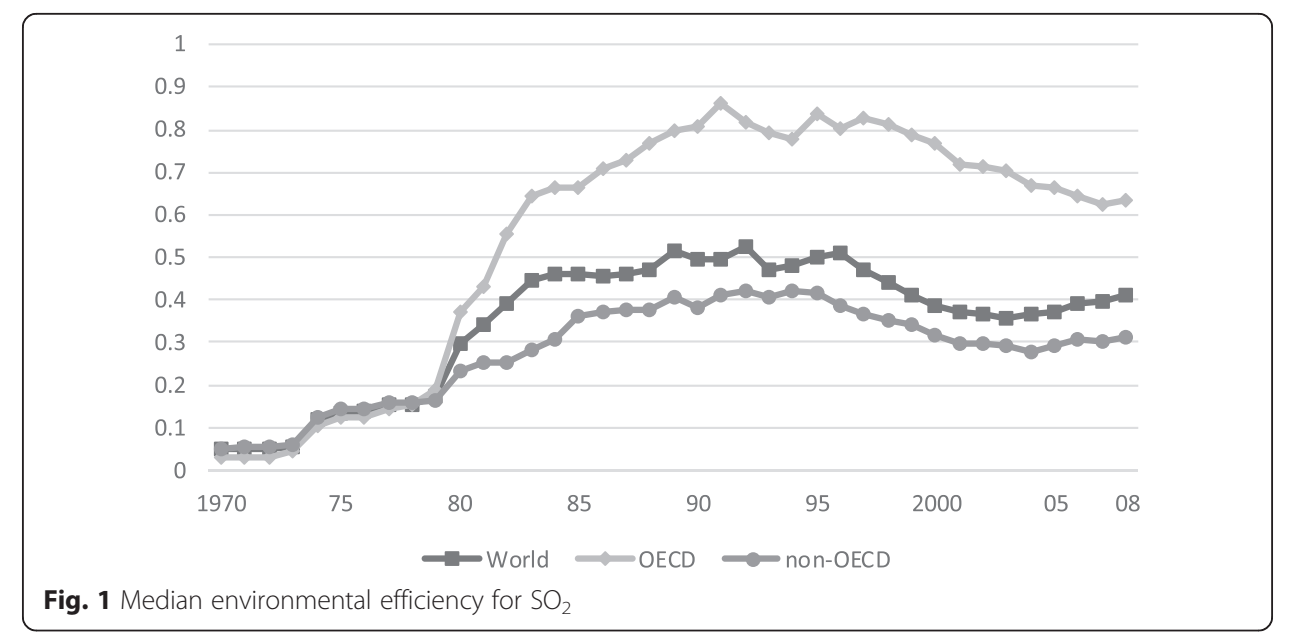


Table 2 Determinants of environmental efficiency

\begin{tabular}{|c|c|c|c|c|c|c|c|c|}
\hline & $\mathrm{SO}_{2}$ & NOx & PM10 & $\mathrm{CO}_{2}$ & $\mathrm{SO}_{2}$ & $\mathrm{NOx}$ & PM10 & $\mathrm{CO}_{2}$ \\
\hline \multicolumn{9}{|l|}{ Fixed } \\
\hline \multirow[t]{2}{*}{$\ln 1$} & $0.343^{* * *}$ & $0.269^{* * *}$ & $0.221^{* * *}$ & $0.389^{* * *}$ & $0.423^{* * *}$ & $0.328^{* * *}$ & $0.288^{* * *}$ & $0.446^{* * *}$ \\
\hline & $(0.065)$ & $(0.057)$ & $(0.054)$ & $(0.110)$ & $(0.067)$ & $(0.057)$ & $(0.054)$ & $(0.094)$ \\
\hline \multirow[t]{2}{*}{$\ln \mathrm{K} / \mathrm{L}$} & -0.073 & 0.007 & 0.017 & -0.025 & $-0.253^{* * *}$ & $-0.158^{* * *}$ & $-0.136^{* *}$ & $-0.230^{* * *}$ \\
\hline & $(0.075)$ & $(0.056)$ & (0.059) & $(0.071)$ & $(0.066)$ & $(0.049)$ & $(0.053)$ & $(0.072)$ \\
\hline \multirow[t]{2}{*}{$\ln T$} & $0.095^{*}$ & 0.053 & 0.055 & -0.049 & 0.130 & 0.068 & 0.086 & -0.060 \\
\hline & $(0.055)$ & $(0.038)$ & $(0.045)$ & $(0.079)$ & $(0.081)$ & $(0.049)$ & $(0.060)$ & $(0.114)$ \\
\hline \multirow[t]{2}{*}{ Constant } & $-2.043^{* * *}$ & $-2.122^{* * *}$ & $-1.839^{* * *}$ & $-2.326^{* * *}$ & $-1.255^{* *}$ & $-1.181^{* *}$ & $-1.159^{*}$ & -0.932 \\
\hline & $(0.176)$ & $(0.516)$ & $(0.549)$ & $(0.697)$ & $(0.630)$ & $(0.579)$ & $(0.606)$ & $(0.583)$ \\
\hline Time dummies & No & No & No & No & Yes & Yes & Yes & Yes \\
\hline Adj R2 & 0.195 & 0.26 & 0.208 & 0.23 & 0.309 & 0.422 & 0.326 & 0.138 \\
\hline \multicolumn{9}{|l|}{ Random } \\
\hline \multirow[t]{2}{*}{$\ln 1$} & $0.353^{* * *}$ & $0.285^{* * *}$ & $0.240^{* * *}$ & $0.395^{* * *}$ & $0.428^{* * *}$ & $0.337^{* * *}$ & $0.302^{* * *}$ & $0.451^{* * *}$ \\
\hline & $(0.064)$ & $(0.057)$ & $(0.055)$ & $(0.116)$ & $(0.063)$ & $(0.055)$ & $(0.053)$ & $(0.103)$ \\
\hline \multirow[t]{2}{*}{$\ln \mathrm{K} / \mathrm{L}$} & $-0.113^{*}$ & -0.04 & -0.023 & -0.106 & $-0.258^{* * *}$ & $-0.168^{* * *}$ & $-0.146^{* * *}$ & $-0.266^{* * *}$ \\
\hline & $(0.065)$ & $(0.053)$ & $(0.055)$ & $(0.071)$ & $(0.059)$ & $(0.046)$ & $(0.050)$ & $(0.079)$ \\
\hline \multirow[t]{2}{*}{$\ln T$} & $0.093^{* *}$ & 0.052 & 0.052 & -0.021 & 0.113 & 0.056 & 0.071 & -0.051 \\
\hline & $(0.047)$ & $(0.033)$ & $(0.037)$ & $(0.056)$ & $(0.071)$ & $(0.042)$ & $(0.051)$ & $(0.085)$ \\
\hline \multirow[t]{2}{*}{ Constant } & $-1.689^{* * *}$ & $-1.744^{* * *}$ & $-1.571^{* * *}$ & $-1.633^{* * *}$ & $-1.174^{* *}$ & $-1.121^{* * *}$ & $-1.130^{* *}$ & -0.65 \\
\hline & $(0.394)$ & $(0.387)$ & $(0.414)$ & $(0.473)$ & $(0.468)$ & $(0.426)$ & $(0.439)$ & $(0.426)$ \\
\hline Time dummies & No & No & No & No & Yes & Yes & Yes & Yes \\
\hline adj R2 & 0.195 & 0.26 & 0.208 & 0.055 & 0.317 & 0.433 & 0.338 & 0.151 \\
\hline $\mathrm{N}$ & 3439 & 3439 & 3439 & 3439 & 3439 & 3439 & 3439 & 3439 \\
\hline Hausman & $23.81^{* * *}$ & $59.75^{* * *}$ & $35.36^{* * *}$ & $24.95^{* * *}$ & 6.66 & 14.49 & 15.55 & 4.53 \\
\hline
\end{tabular}

(Note) The robust standard errors are in parenthesis. The statistical significance at the one, five, and ten percent levels are indicated by ${ }^{* * *}, * *$, and $*$, respectively

models. It indicates that there is no indirect trade-induced composition effect on the environmental efficiency.

In conclusion, we find strong evidence of the trade-induced scale-technique effect. Namely, relatively high income countries benefit from trade, specializing clean industry by stringent environmental regulation. As opposed to the $\mathrm{PHH}$ studies (Antweiler et al. 2001; Cole and Elliott 2003; Managi et al. 2009), the tradeinduced composition effect is not observed for the environmental efficiency. The reason for this may be that the trade-induced composition effect is smaller relative to the scale-technique effects and the direct composition effect as shown in Cole and Elliott (2003).

\section{Conclusions}

Using a data envelopment analysis (DEA) model that allows us to treat undesirable outputs and super-efficiency beyond unity, this study measures the environmental efficiency of four air pollutants- $\mathrm{SO}_{2}, \mathrm{NO}_{\mathrm{x}}, \mathrm{PM} 10$, and $\mathrm{CO}_{2}-$ for 98 countries for the period 1970-2008. A slacks-based measure (SBM) DEA efficiency index with undesirable outputs is constructed by modifying $\mathrm{Li}$ et al. (2013) definition. It provides us with more discriminating power than did previous DEA efficiency indices, 
Table 3 Determinants of environmental efficiency with cross-terms

\begin{tabular}{|c|c|c|c|c|c|c|c|c|}
\hline & $\mathrm{SO}_{2}$ & NOx & PM10 & $\mathrm{CO}_{2}$ & $\mathrm{SO}_{2}$ & $\mathrm{NOx}$ & PM10 & $\mathrm{CO}_{2}$ \\
\hline \multicolumn{9}{|l|}{ Fixed } \\
\hline \multirow[t]{2}{*}{$\ln 1$} & $0.180^{* *}$ & $0.163^{* * *}$ & $0.117^{*}$ & $0.270^{* *}$ & $0.267^{* * *}$ & $0.228^{* * *}$ & $0.192^{* * *}$ & $0.335^{* * *}$ \\
\hline & $(0.077)$ & $(0.060)$ & $(0.059)$ & $(0.106)$ & $(0.075)$ & $(0.053)$ & $(0.055)$ & $(0.083)$ \\
\hline \multirow[t]{2}{*}{$\ln \mathrm{K} / \mathrm{L}$} & -0.036 & 0.022 & 0.015 & 0.031 & $-0.252^{* * *}$ & $-0.177^{* * *}$ & $-0.170^{* *}$ & $-0.214^{* * *}$ \\
\hline & $(0.094)$ & $(0.071)$ & $(0.079)$ & $(0.103)$ & $(0.082)$ & $(0.065)$ & $(0.071)$ & $(0.077)$ \\
\hline \multirow[t]{2}{*}{$\ln T$} & $0.094^{*}$ & 0.052 & 0.053 & -0.049 & 0.095 & 0.042 & 0.058 & -0.082 \\
\hline & $(0.053)$ & $(0.037)$ & $(0.044)$ & $(0.077)$ & $(0.071)$ & $(0.047)$ & $(0.057)$ & $(0.109)$ \\
\hline \multirow[t]{2}{*}{$|n \mathrm{~T} R|$} & $0.059^{*}$ & $0.038^{* * *}$ & $0.036^{* * *}$ & $0.046^{* * *}$ & 0.046 & $0.028^{* * *}$ & $0.025^{* *}$ & $0.035^{* *}$ \\
\hline & $(0.033)$ & $(0.012)$ & $(0.013)$ & $(0.017)$ & $(0.031)$ & $(0.010)$ & $(0.010)$ & $(0.016)$ \\
\hline \multirow[t]{2}{*}{ InT RKL } & 0.002 & 0.007 & 0.016 & -0.016 & 0.015 & 0.02 & 0.027 & 0.002 \\
\hline & $(0.033)$ & $(0.022)$ & $(0.026)$ & $(0.038)$ & $(0.031)$ & $(0.022)$ & $(0.025)$ & $(0.034)$ \\
\hline \multirow[t]{2}{*}{ Constant } & -1.281 & $-1.543^{* *}$ & -1.129 & $-2.012^{*}$ & -0.049 & -0.23 & -0.102 & -0.224 \\
\hline & $(0.785)$ & $(0.608)$ & $(0.685)$ & $(1.068)$ & $(0.718)$ & $(0.658)$ & $(0.677)$ & $(0.686)$ \\
\hline Time dummies & No & No & No & No & Yes & Yes & Yes & Yes \\
\hline Adj R2 & 0.189 & 0.246 & 0.19 & 0.057 & 0.298 & 0.385 & 0.288 & 0.137 \\
\hline \multicolumn{9}{|l|}{ Random } \\
\hline \multirow[t]{2}{*}{$\ln \mid$} & $0.201^{* * *}$ & $0.187^{* * *}$ & $0.145^{* *}$ & $0.283^{* * *}$ & $0.275^{* * *}$ & $0.240^{* * *}$ & $0.212^{* * *}$ & $0.340^{* * *}$ \\
\hline & $(0.074)$ & $(0.062)$ & $(0.062)$ & $(0.110)$ & $(0.072)$ & $(0.052)$ & $(0.055)$ & $(0.090)$ \\
\hline \multirow[t]{2}{*}{$\ln \mathrm{K} / \mathrm{L}$} & -0.076 & -0.019 & -0.022 & -0.039 & $-0.256^{* * *}$ & $-0.182^{* * *}$ & $-0.176^{* * *}$ & $-0.240^{* * *}$ \\
\hline & $(0.085)$ & $(0.068)$ & $(0.075)$ & $(0.087)$ & $(0.075)$ & $(0.061)$ & $(0.067)$ & $(0.072)$ \\
\hline \multirow[t]{2}{*}{$\ln T$} & $0.086^{* *}$ & 0.048 & 0.046 & -0.022 & 0.074 & 0.028 & 0.041 & -0.074 \\
\hline & $(0.043)$ & $(0.032)$ & $(0.037)$ & $(0.052)$ & $(0.061)$ & $(0.041)$ & $(0.049)$ & $(0.079)$ \\
\hline \multirow[t]{2}{*}{$\ln \mathrm{TRl}$} & $0.055^{*}$ & $0.035^{* * *}$ & $0.033^{* * *}$ & $0.044^{* *}$ & 0.045 & $0.027^{* * *}$ & $0.023^{* *}$ & $0.035^{* *}$ \\
\hline & $(0.030)$ & $(0.012)$ & $(0.012)$ & $(0.018)$ & $(0.029)$ & $(0.010)$ & $(0.010)$ & $(0.017)$ \\
\hline \multirow[t]{2}{*}{ InT RKL } & -0.005 & -0.001 & 0.01 & -0.025 & 0.012 & 0.016 & 0.024 & -0.004 \\
\hline & $(0.032)$ & $(0.019)$ & $(0.023)$ & $(0.037)$ & $(0.030)$ & $(0.020)$ & $(0.022)$ & $(0.033)$ \\
\hline \multirow[t]{2}{*}{ Constant } & -0.956 & $-1.254^{* *}$ & -0.912 & -1.442 & 0.013 & -0.225 & -0.125 & -0.014 \\
\hline & $(0.691)$ & $(0.522)$ & $(0.587)$ & $(0.898)$ & $(0.618)$ & $(0.564)$ & $(0.560)$ & $(0.606)$ \\
\hline Time dummies & No & No & No & No & Yes & Yes & Yes & Yes \\
\hline Adj R2 & 0.21 & 0.278 & 0.213 & 0.078 & 0.312 & 0.406 & 0.309 & 0.153 \\
\hline $\mathrm{N}$ & 3439 & 3439 & 3439 & 3439 & 3439 & 3439 & 3439 & 3439 \\
\hline Hausman & $50.72^{* * *}$ & $93.65^{* * *}$ & $61.49 * * *$ & $30.76^{* * *}$ & 17.68 & 26.43 & 25.42 & 6.99 \\
\hline
\end{tabular}

(Note) The robust standard errors are in parenthesis. The statistical significance at the one, five, and ten percent levels are indicated by $*^{* *}, *^{*}$, and ${ }^{*}$, respectively

allowing efficiency score beyond unity. For the resulting environmental efficiency, the median of the non-OECD countries improves similar to that of the OECD countries until 1978. However, since 1979, the former is consistently below the latter.

In this study, an impact of international trade on environmental efficiency is examined. The panel regression results reveal that trade openness is positively correlated to the environmental efficiency. However, the impact of trade openness on environmental efficiency varies across countries depending on their relative income level. The estimated results show that the higher the relative income per capita, the more the benefit of trade on the environmental efficiency. 
The environmental efficiency results in this study have to be interpreted with great caution. First, environmental efficiency can be improved even when pollution emissions increase, as long as more outputs are produced. Second, in this study, an efficiency improvement includes a change in the industrial structure from polluting industries to less-polluting industries and that in the technical improvement in each industry. Third, because environmental regulation varies across countries, firms in a country where pollution emissions are not strictly regulated do not have an incentive to reduce emissions and then such a country is evaluated as inefficiency in this paper. Fourthly, since DEA is a deterministic approach, the efficiency estimates suffers from outliers. The order-m method proposed by Cazals et al. (2002), Daraio and Simar (2007), and Tauchmann (2011) mitigates the sensitivity of outliers, subsampling artificial reference samples with $\mathrm{m}$ peer DMUs. This would be a fruitful line of future research currently pursued by Yagi et al. (2015). They measure an order-m environmental efficiency for each of ten undesirable inputs/outputs and exhibit the shadow prices of each of them.

\section{Additional file}

Additional file 1: Figure S1. The environmental efficiency indices of 98 countries for $\mathrm{SO}_{2}$ and $\mathrm{CO}_{2}$. (1970-2008).

Competing interests

The author declares that he has no competing interests.

\section{Acknowledgements}

The author thanks anonymous referees, Satoru Komatsu, Ming-Chung Chang, and the participants at the 2013 Annual Meeting of the Society for Environmental Economics and Policy Studies in Kobe and at the 4th Congress of the East Asian Association of Environmental and Resource Economics in Pusan. This study was supported by JSPS KAKENHI Grant Number (25380346).

Received: 14 May 2015 Accepted: 5 August 2015

Published online: 20 August 2015

\section{References}

Antweiler W, Copeland BR, Taylor MS (2001) Is free trade good for the environment? Am Econ Rev 91(4):877-908 Cazals C, Florens JP, Simar L (2002) Nonparametric frontier estimation: a robust approach. J Econ 106(98):1-25

Chang YT, Zhang N, Danao D, Zhang N (2013) Environmental efficiency analysis of transportation system in China: a non-radial DEA approach. Energy Policy 58:277-283

Choi Y, Zhang N, Zhou P (2012) Efficiency and abatement costs of energy-related $\mathrm{CO}_{2}$ emissions in China: a slacksbased efficiency measure. Appl Energy 98:198-208

Chung YH, Färe R, Grosskopf S (1997) Productivity and undesirable outputs: a directional distance function approach. J Environ Manage 51(3):229-240

Cole MA, Elliott RJR (2003) Determining the trade-environment composition effect: the role of capital, labor and environmental regulations. J Environ Econ Manag 46:363-383

Daraio C, Simar L (2007) Advance robust and nonparametric methods in efficiency analysis. Springer, New York, USA

Färe R, Grosskopf S, Lovell CK, Yaisawarng S (1993) Derivation of shadow prices for undesirable outputs: a distance function approach. Review of economics and statistics., pp 374-380

Frankel JA, Rose AK (2005) Is trade good or bad for the environment? Sorting out the causality. Rev Econ Stat 87(1):85-91

Grossman GM, Krueger AB (1993) Environment impacts of a North American Free Trade Agreement. In: Garber PM (ed) The Mexican-U.S. Free Trade Agreement. MIT Press, Cambridge, MA

Halkos GE, Tzeremes NG (2009) Exploring the existence of Kuznets curve in countries' environmental efficiency using DEA window analysis. Ecol Econ 68(7):2168-2176

Halkos GE, Tzeremes NG (2011) Kuznets curve and environmental performance: evidence from China., MPRA paper No.34312

Li LB, Hu JL (2012) Ecological total-factor energy efficiency of regions in China. Energy Policy 46:216-224

Li H, Fang K, Yang W, Wang D, Hong X (2013) Regional environmental efficiency evaluation in China: analysis based on the super-SBM model with undesirable outputs. Math Comput Model 58(5-6):1018-1031

Managi S, Jena PR (2008) Environmental productivity and Kuznets curve in India. Ecol Econ 65(2):432-440

Managi S, Hibiki A, Tsurumi T (2009) Does trade openness improve environmental quality? J Environ Econ Manag 58(3):346-363

Picazo-Tadeo AJ, Reig-Martinez E, Hernandez-Sancho F (2005) Directional distance functions and environmental regulation. Resour Energy Econ 27(2):131-142 
Tauchmann H (2011) Partial frontier efficiency analysis for stata. Discussion paper SFB 823: technical university of Dortmund, No.25/2011

Tone K (2001) A slacks-based measure of efficiency in data envelopment analysis. Eur J Oper Res 130(3):498-509 Tone K (2002) A slacks-based measure of super-efficiency in data envelopment analysis. Eur J Oper Res 143(1):32-41

Tone K (2004) Dealing with undesirable outputs in DEA: a slacks-based measure (SBM) approach. Operations research society of Japan., pp 44-45

Tsurumi T, Managi S (2014) The effect of trade openness on deforestation: empirical analysis for 142 countries". Environ Econ Pol Stud 16(4):305-324

Wei C, Jinlan NI, Limin DU (2012) Reginal allocation of carbon dioxide abatement in China. China Econ Rev 23(3):552-565

Yagi M, Fujii H, Hoang V, Managi S (2015) Environmental efficiency of energy, materials, and emissions". J Environ Manage 161:206-218

Zaim O, Taskin F (2000) A Kuznets curve in environmental efficiency: an application on OECD countries. Environ Resour Econ 17(1):21-36

Zhou P, Ang BW, Poh KL (2006) Slacks-based efficiency measures for modeling environmental performance. Ecol Econ 60(1):111-118

Submit your manuscript to a SpringerOpen ${ }^{\circ}$ journal and benefit from:

- Convenient online submission

- Rigorous peer review

- Immediate publication on acceptance

- Open access: articles freely available online

- High visibility within the field

- Retaining the copyright to your article

Submit your next manuscript at $>$ springeropen.com 